\title{
Orientasi Belajar dan Komitmen Terhadap Kinerja UKM melalui Human Capital Sebagai Variabel Intervening Pada UKM Kerajinan di Malang Raya
}

\author{
Wahju Wulandari ${ }^{1}$, Sodik ${ }^{2}$, Dharmayanti Pri Handini ${ }^{3}$ \\ ${ }^{1,2,3)}$ Program Studi Manajemen dan Akuntansi Universitas Widyagama Malang \\ Email : ndari.sodik@gmail.com ${ }^{1}$,hmsodik4@gmail.com ${ }^{2}$,dharmayanti35@gmail.com ${ }^{3}$
}

\begin{abstract}
Abstrak
Tujuan penelitian ini adalah untuk mengetahui model hubungan antara orientasi belajar, komitmen memiliki hubungan dengan kinerja UKM melalui human capital sebagai variabel intervening. Metode penelitian deskriptif dan kuantitatif ini akan memberikan gambaran untuk menguji hipotesis penelitian dengan populasi UMKM kerajinan di Malang Raya dengan sampel sebanyak 100 UMKM melalui teknik purposive sampling. Data tersebut diuji dengan alat analisis Smart Pls. Hasil penelitian menunjukkan bahwa orientasi belajar tidak memiliki hubungan yang kuat dengan kinerja UKM, dapat dipahami bahwa orientasi belajar sebagian besar karyawan UKM masih belum maksimal untuk diperhatikan. Sedangkan komitmen dalam melakukan peningkatan kinerja melalui beberapa faktor seperti keinginan, kemauan dan keterikatan emosional memiliki pengaruh yang positif sehingga dapat mempengaruhi sumber daya manusia dalam meningkatkan kinerja UKM.
\end{abstract}

Kata kunci: orientasi pembelajaran, komitmen, human capital, kinerja UKM

\begin{abstract}
The purpose of this research is to find a model of the relationship between learning orientation, commitment has a relationship to the performance of SMEs through human capital as an intervening variable. This descriptive and quantitative research method will provide a picture to test the research hypothesis with a population of handicraft SMEs in Malang Raya with a sample of 100 SMEs through a purposive sampling technique. The data is tested with the Smart Pls analysis tool. The results showed that learning orientation is not a strong relationship to SME performance, it can be understood that learning orientation for most SME employees is still not maximized to be noticed. Whereas commitment in carrying out performance improvement through several factors such as desire, willingness and emotional ties has a positive impact so that it can influence human capital in improving the performance of SMEs.
\end{abstract}

Keywords: learning orientation, commitment, human capital, SME performance

\section{PENDAHULUAN}

Bisnis berskala kecil dan menengah di Indonesia menjadi sandaran perekonomian dari suatu bangsa. UKM sebuah bisnis kecil telah memberikan pengaruh besar sebagai sumbangan pendapatan negara. Hal ini dikarenakan kondisi UKM sangat tangguh dalam menghadapi segala kesulitan, hanya saja bisnis yang dijalankan masih banyak kekurangan terutama dalam hal pengembangan SDM. Pemberdayaan UKM saat ini masih menjadi kendala terhadap aktivitas untuk melakukan peningkatan kemampuan dalam bidang SDM, pemasaran dan keuangan.

Kemampuan SDM bagi UKM
merupakan salah satu upaya dalam
meningkatkan kemampuan untuk
mengelola usaha menjadi lebih bagus.
SDM sebagai karyawan yang mampu
menggerakkan usaha ke arah yang lebih
layak dan menjalankan usaha untuk
mencapai tujuan suatu bisnis agar
menjadi survival. Potensi SDM dalam
UKM menjadikan peran yang sangat
utama dalam menjalankan bisnis.
Schultz (1961) manusia sebagai modal
memiliki dimensi kualitatif yang
mencerminkan tingkat kemampuan,
ketrampilan, kecerdasan dalam
mengelola bisnis. Peningkatan
kemampuan manusia dapat diraih


melalui pendidikan, pelatihan, ketrampilan dengan model magang yang semua upaya ini dilakukan sebagai investasi di masa yang akan datang. Marko (2013), sumber daya sebagai modal intelektual dan akan menjadi keunggulan kompetitif dalam peningkatan kemampuan dan mempunyai pengaruh positif untuk keberhasilan bisnis di masa depan.

Masalah penelitian ini dikarena suatu gap dalam sebuah research yaitu: Dalam Firdayanti (2016) menurut Pujilistyani (2008), Kesi (2013) kualitas aset strategik dipengaruhi secara positif oleh pembelajaran dari suatu organisasi, namun Sudharta dan Li (2004) menyatakan tidak berpengaruh. Muharram dan Samad, (2015) kualitas harta atau aset strategik berpengaruh positif terhadap kinerja bisnis, namun Chandler, G., \& Hanks (1994) penelitian memberikan kesimpulan negatif pada kinerja sebuah bisnis. Hasil penelitian Frimayasa dan Lawu (2020) menyatakan bahwa komitmen dan human capital baik secara direct maupun indirect mempunyai pengaruh positif dan signifikan terhadap kinerja suatu karyawan. Penelitian ini merujuk pada Julita, Santi. (2010) dan Visagle, C. M., Steyn (2011) kesiapan dalam melakukan suatu perubahan.

Oleh karena itu tujuan penelitian ini akan mengkaji secara keseluruhan terhadap fenomena yang sebelumnya belum diteliti dengan menggabungkan antara orientasi belajar baik yang ditujukan untuk sebuah organisasi bisnis atau UKM, komitmen dalam menjalankan bisnis, serta human capital sebagai mediasi atau intervening terhadap kinerja UKM baik dilihat pada profitabilitas UKM, peluang pasar dan posisi pasar UKM. Penelitian tentang pembelajaran, human capital memberikan pemahaman bahwa human capital dengan peningkatan orientasi belajar akan menjadi investasi dalam jangka panjang Piazza-Georgi (2002). Oleh karena itu, masih menjadi kendala bagi UKM dalam meningkatkan kemampuan SDM, sehingga kinerja UKM menjadi terkendala untuk dapat berkembang sampai dengan menembus pasar yang lebih kompetitif baik di dalam negeri maupun di luar negeri atau menjadi produk global.

\section{TINJAUAN PUSTAKA}

\section{Orientasi Belajar}

Orientasi belajar sebagai proses belajar Friere 1970, yang dapat mempengaruhi suatu sistem hubungan dengan lingkungan sehingga Fiol dan Lyles 1985 membuat kesimpulan bahwa dimensi kognitif dalam belajar merupakan suatu dimensi yang berhubungan denga budaya, strategi, struktur dan lingkungan. Namun Sinkula et. al. 1997 ukuran orientasi belajar sebagai komitmen, membagi sebuah visi, dan keterbukaan dalam sebuah pemikiran. Oleh karena itu untuk menjembatani hal tersebut UKM kerajinan selalu berbuat lebih dalam bagi sebuah proses pembelajaran bisnis yang selanjutnya dapat dikembangkan. Orientasi belajar dalam hal ini lebih ditekankan pada sebuah pemahaman tentang hal yang baru, melakukan training dan pengembangan diri secara terus menerus.

\section{Komitmen}

Dalam Pramadani dan Fajrianthi (2012) Griffin mengemukakan bahwa komitmen sebagai suatu kepercayaan dan rasa memiliki yang dicerminkan dalam suatu bentuk menjaga nilai-nilai dalam mencapai tujuan organisasi yang dicerminkan ke dalam bisnis. Sedangkan unsur komitmen menurut Cepi (2015) adalah sebagai berikut:

1. Keinginan kuat untuk tetap bertahan dalam suatu organisasi

2. Menerima tujuan organisasi atau isnstitusi bisa juga dalam UKM 
3. Tinngi rendahnya terhadap kemangkiran yang akan diperbuat.

\section{Human Capital}

Menurut Dae-Bong (2009) menyatakan bahwa human capital atau modal insani mempunyai aspek individu, Perspektif ini menekankan pada pengetahuan dan keterampilan yang diperoleh selama mengikuti pendidikan seperti pendidikan wajib, postsecondary pendidikan, dan pendidikan kejuruan.

Menurut Ferdinand (2005) Instrumen pemasaran mampu berkolaborasi dengan konsep human capital dan modal sosial untuk dapat menghasilkan produk yang mampu bersaing. Kozlenkova, Samaha, and Palmatier (2013) menyatakan bahwa kesuksesan dari sebuah bisnis telah ditekankan pada tingkat kemampuan SDM yang dimilikinya. Sedangkan menurut Surin et al. (2017) Kegagalan dari sebuah bisnis dan tidak adanya pertumbuhan bisnis ini dikarenakan UKM tidak melakukan peningkatan kemampuan dan ketrampilan SDMnya. Nurainun (2008) menyatakan bahwa perkembangan UKM dalam bisnis yang akan mengganggu keberlanjutan usahanya akan menjadi mati. Bisnis UKM akan menjadi sukses dalam jangka panjang hal ini sangat tergantung pada investasi modal sosial yang dilakukannya (Ferdinand 2005). Perkembangan terbaru dalam capital social menyimpulkan bahwa nilai human capital dapat ditingkatkan melalui kemauan dan niat baik yang dibangun dengan sederet hubungan-hubungan sosial yang dapat dilakukan untuk memudahkan tindakan kolektif (Widodo 2009). Human capital yang berkualitas, dan berlandasan modal sosial yang kuat dapat diprediksi mampu meningkatkan kinerja pemasaran.

\section{Kinerja}

Kinerja UKM sebagai faktor yang dapat dipakai untuk mengukur suatu kebijakan yang akan diterapkan dalam menjalankan bisnis. Kebijakan dibuat untuk diarahkan dalam pencapaian kinerja yang baik dalam menangani kinerja keuangan, pemasaran, produksi, dan pengembangan SDM. kinerja keuangan bisa diperoleh dari pengukuran profitability dan tingkat pengembalian modal. Menurut Chong (2008) kinerja UKM juga bisa terkait dengan pemasaran dalam mencapai volume penjualan, market share, dan perluasan pasar.

Menurut Widodo (2009) dalam Slater dan J. Paul Peter (2001) menyatakan bahwa kinerja UKM sangat dipengaruhi oleh beberapa faktor penunjang diantaranya adalah profitability, market share, dan posisi pasar. Pemasaran sebagai salah satu ujung tombak dalam meraih keberhasilan bisnis, naum menjadi banyak masalah utama untuk menembus pasar yang lebih luas. Kinerja UKM merupakan salah satu langkah dalam mencapai tujuan usaha. Oleh karena itu, menurut Andriani (2012) menyatakan bahwa kinerja pemasaran sangat menjadi masalah dalam mengoperasionalkan karena kemampuan daya jangkau dan media pemasaran yang masih kurang tepat. UKM mampu untuk melakukan produksi namun kendala menjual dan memasarkan produk yang masih kesulitan. UKM masih banyak melakukan upaya pemasaran dengan melalui suatu kemitraan

\section{METODE PENELITIAN}

Penelitian yang didasarkan atas kejelasan secara deskriptif dan ditunjang dengan menggunakan data kuantitatif dilaksanakan dengan proses survey terhadap UKM yang dipilih dalam bidang kerajinan yang tersebar di Malang Raya yaitu di Kota Malang, Kota Batu dan Kabupaten Malang. Populasi penelitian ini adalah jumlah UKM kerajinan yang berada di Malang Raya. Menurut Roscoe dalam (Sugiyono 2006) bahwa sampel penelitian layak antara 30 sampai 500, oleh karena itu 
penelitian ini menetapkan sampel berjumlah 100 dengan ketentuan sebagai UKM yang bergerak dalam bidang kerajinan. Data primer diperoleh dengan kuisioner sedangkan untuk data sekunder diperoleh dari referensi penelitian terdahulu dan buku-buku literatur. Penelitian ini menetapkan bentuk teknik sampling yang diambil adalah Purposive Sampling, sedangkan data primer melalui pengisian kuesioner diberikan kepada UKM dalam bidang kerajinan. Jumlah responden diambil berdasarkan proporsional random sampling untuk masing-masing kelompok UKM kerajinan yang berada di wilayah Malang Raya. UKM kerajinan mempersepsikan kinerja nya ke dalam skala likert. Pertanyaan disediakan dengan lima jawaban pilihan sangat setuju (5), setuju (4), kurang setuju (3), tidak setuju (2), dan sangat tidak setuju (1). Analisis yang digunakan yaitu Structural Equation Modeling (partly least square, PLS) dengan menggunakan pendekatan aplikasi program sofware SmartPLS.

UKM yang tersebar di Malang Raya ditentukan secara porposive sampling dapat ditunjukkan pada gambar 1 dibawah ini:

Gambar 1: Pemilik UKM Kerajinan di Malang Raya

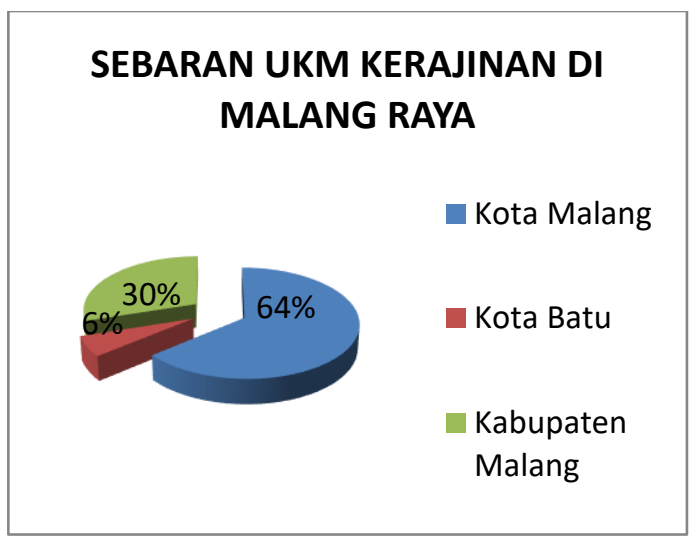

Sumber: data diolah (2020)

Sedangkan variabel dalam penelitian ini terdiri dari: orientasi belajar dengan indikator mengetahui hal baru, melakukan trainining, pengembangan secara terus-menerus; komitmen dengan indikator memiliki keinginan, memiliki kemauan, dan memiliki ikatan emosional; human capital indikatornya meliputi kreatif dalam bekerja, melakukan on the job trainning, melakukan in the job trainning, memiliki pengetahuan bekerja dan pengalaman pelatihan secara umum.

Tabel 1. Variabel dan Indikator

\begin{tabular}{|c|c|}
\hline Variabel & Indikator \\
\hline $\begin{array}{l}\text { Orientasi } \\
\text { Belajar }\end{array}$ & $\begin{array}{l}\text { Mengetahui hal baru } \\
\text { Melakukan Trainning } \\
\text { Pengembangan Secara Terus- } \\
\text { menerus }\end{array}$ \\
\hline Komitmen & $\begin{array}{l}\text { Memiliki Keinginan } \\
\text { Memiliki kemauan } \\
\text { Memiliki ikatan emosional }\end{array}$ \\
\hline $\begin{array}{l}\text { Human } \\
\text { Capital } \\
\text { Widodo } \\
(2009)\end{array}$ & $\begin{array}{l}\text { Kreatif dalam menjalankan } \\
\text { pekerjaan } \\
\text { Melakukan pelatihan dalam } \\
\text { bentuk on the job trainning } \\
\text { Melakukan pelatihan dalam in } \\
\text { the job trainning } \\
\text { Memiliki pengetahuan untuk } \\
\text { menjalankan pekerjaan } \\
\text { Pengalaman mengikuti } \\
\text { pelatihan secara umum }\end{array}$ \\
\hline $\begin{array}{l}\text { Kinerja } \\
\text { UKM }\end{array}$ & $\begin{array}{l}\text { Profitability } \\
\text { Market share } \\
\text { Posisi pasar }\end{array}$ \\
\hline
\end{tabular}

Sumber: widodo (2009); R. Hewlett. (2002)

Hipotesa penelitian yang disajikan adalah sebagai berikut:

H1: adakah pengaruh orientasi belajar terhadap human capital

H2 : adakah pengaruh Komitmen terhadap human kopital

H3 : adakah pengaruh human kapital terhadap kinerja

H4 : adakah pengaruh orientasi belajar terhadap kinerja UKM 
H5 : adalah pengaruh Komitmen terhadap kinerja UKM

H6 : adakah pengaruh orientasi belajar terhadap kinerja UKM melalui human capital

H7 : adakah pengaruh komitmen terhadap kinerja UKM melalui human capital

Hipotesis dapat dilihat pada gambar 2 sebagai berikut:

Gambar 2. Hipotesa model terkait kinerja UKM

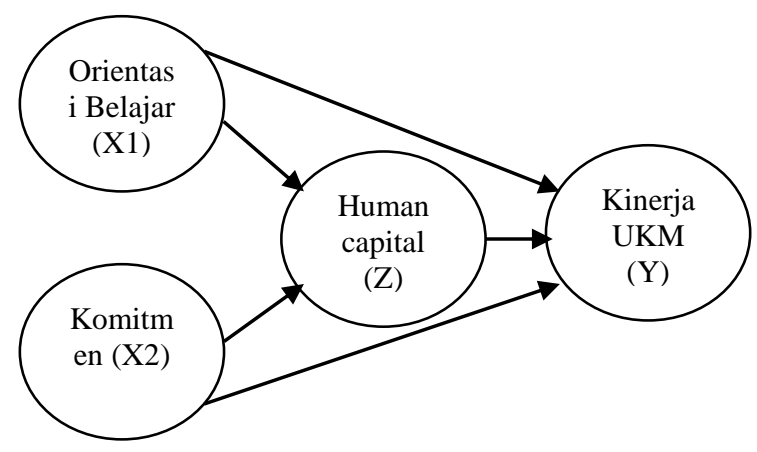

HASIL DAN PEMBAHASAN

Karakteristik UKM kerajinan yang berada di Malang Raya telah terbagi menjadi di Kota Malang, Kota Batu delapan jenis kerajinan ayitu: Craft dan asesories sebanyak 44\%; kerajinan logam karena tidak banyak jadi hanya sebesar 2\%; kerajinan di bidang kayu sebesar 10\%; kerajinan untuk bahan terbuat dari kain sebanyak 23\%; rajut $10 \%$; UKM batik $8 \%$; glass painting $1 \%$; dan UKM yang mengolah tanah menjadi gerabah sebanyak $2 \%$.

\section{Analisis struktural equation model dengan Smart PLS}

Variabel Orientasi belajar, Komitmen, Human Capital dan Kinerja UKM merupakan suatu konsep yang menerangkan tentang hubungan dan saling memberi pengaruh terhadap variabel lain melalui suatu model struktural yang dapat dilihat pada gambar 2. Gambaran yang menjelaskan tentang adanya suatu hubungan antara variabel laten dengan indikatornya.
Sedangkan yang menjadi variabel laten adalah orientasi belajar sebagai (X1), komitmen sebagai (X2), human capital (Z), dan kinerja UKM sebagai variabel (Y). Hasil analisis Smart PLS telah menunjukkan adanya faktor yang menyatakan sebuah hubungan antara indikator dan variabel laten hal ini bisa dilihat pada (gambar 2). Terdapat tiga indikator pada variabel orientasi belajar berdasarkan hasil uji PLs memiliki faktor loading terendah dan terjadi pada indikator X1.2, dan X1.3, dengan nilai faktor loading sebesar -0.786, 0.126 . Indikator ini menyebabkan tidak reliabel sehingga harus dibuang agar model menjadi memenuhi kelayakan untuk digunakan. Model baru akan disajikan pada Gambar 4 untuk semua variabel, dari hasil analisa Pls selanjutnya menunjukkan faktor loading yang cukup tinggi, melebihi nilai ideal 1.000 maksuda dari hasil tersebut menjelaskan bahwa semua indikator dalam penelitian ini dapat mempengaruhi karakter variabel sehingga semua variabel laten dapat digunakan dalam model dapat dilihat pada tabel 2 .

Tabel 2: Hasil validitas dan reliabilitas

\begin{tabular}{|c|c|c|c|}
\hline $\begin{array}{c}\text { Laten } \\
\text { variabel }\end{array}$ & $\begin{array}{c}\text { Alpha } \\
\text { Cronbach's }\end{array}$ & $\begin{array}{c}\text { Composit } \\
\text { Reliability } \\
\text { CR }\end{array}$ & AVE \\
\hline $\begin{array}{c}\text { Orientasi } \\
\text { Belajar } \\
\text { (X1) }\end{array}$ & 1,000 & 1,000 & 1,000 \\
\hline $\begin{array}{c}\text { Komitmen } \\
\text { (X2) }\end{array}$ & 0,859 & 0,859 & 0,680 \\
\hline $\begin{array}{c}\text { Human } \\
\text { Capital } \\
\text { (Z) }\end{array}$ & 0,876 & 0,921 & 0.797 \\
\hline $\begin{array}{c}\text { Kinerja } \\
\text { UKM } \\
\text { (Y) }\end{array}$ & 0,823 & 0,893 & 0.739 \\
\hline
\end{tabular}

Sumber: data diolah (2020)

Tabel 2 sebagai hasil awal pengujian validitas dan reliabilitas melalui initial model of variable relation. Uji validitas 
dan reliabilitas dengan Smart PLs hanya ditunjukkan dari variabel saja, sedangkan indikator variabel bisa dilihat dari VIF. Hasil uji validitas dan reliabilitas yang terdapat pada tabel 2 dari hasil analisis PLs, tabel 3 dan tabel 4 dan ditunjukkan dengan gambar 3 . Tabel 3 menunjukkan indikator variabel untuk melihat terbebas dari multikolinier dari hasil VIF, sedangkan tabel 4 memperoleh hasil bahwa uji validitas dan reliabilitas sudah memenuhi syarat pengujian dengan analisis struktural equation model dan diperoleh bahwa kinerja, modal insani, modal sosial dan produktivitas dilihat dari alpha cronbach dan Average Variance Extracted (AVE) sudah memenuhi syarat karena hasilnya diatas 0.5 .

Gambar 3: Model awal hubungan variabel

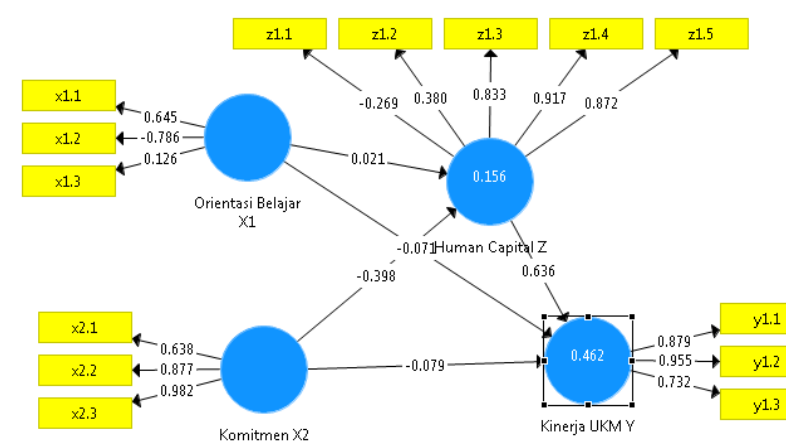

Sumber: data diolah (2020)

Model baru dilakukan uji validitas dan reliabilitas untuk mendaapatkan hasil yang lebih baik. uji validitas menggunakan varian rata-rata yang di ektraksi untuk melihat validitas konvergen komposit dan model dianggap valid jika semua variabel sudah memenuhi persyaratan dari Alpha Cronbach's dan Composit Reliability (CR) diatas 0.7 dan Average Variance Extracted (AVE) diatas 0.5 artinya bahwa data bisa diolah dan memenuhi persyaratan tabel 2. Uji collinnearity statistics (VIF) pada inner value semua variabel kurang dari 5 sehingga data terbebas dari multicollinnearity dan besarnya pengaruh $\mathrm{R}$ square untuk variabel kinerja $(Z) 15.6 \%$ dan variabel pada kinerja UKM sebesar $46.2 \%$. Jadi kinerja UKM sebesar 0.462 menunjukkan variabel (Y) dipengaryhi oleh variabrl orientasi belajar, variabel komitmen dan human capital, sebesar $46.2 \%$, sedangkan sisanya 53,8 \% dipengaruhi oleh variabel lain yangtidak diteliti.

Hasil uji model baru pada tabel 3 merupakan uji hipotesis dari hubungan antara latent variables. Hubungan signifikan antara variabel dengan hasil $(\mathrm{p}$-value $)<0,05$ ditunjukkan oleh variabel komitmen (X2) - human capital (Z), komitmen - melalui human capital (Z) terhadap kinerja UKM (Y). Sedangkan pola hubungan yang terjadi dari orientasi belajar terhadap human kapital tidak mempunyai pengaruh yang signifikan. Orientasi belajar tidah mempunyai hubungan dan pengaruh terhadap kinerja. Orientasi belajar juga tidak mempunyai hubungan dan pengaruh terhadap kinerja melalui human capital. Variabel komitmen juga tidak mempunyai pengaruh terhadap kinerja melalui variabel human capital karena hasil uji statisyis menunjukkan tidak signifikan.

Berdasarkan hasil moderasi effect dinyatakan bahwa variabel orientasi belajar termasuk jenis potensial moderasi karena X1 tidak signifikan dan Moderasi effect dari X1 ke Y melalui Z juga tidak signifikan. Sedangkan pola pengaruh variabel komitmen (X2) mempunyai pengaruh signifikan terhadap human capital dan tidak mempunyai pengaruh pada moderating effect karena hasil uji menunjukkan tidak adanya signifikansi sehingga masuk pada jenis prediktor moderasi.

Tabel 3: Kolinieritas Statistik

\begin{tabular}{|c|c|}
\hline $\begin{array}{c}\text { Indikator } \\
\text { variabel }\end{array}$ & VIF \\
\hline
\end{tabular}




\begin{tabular}{|l|l|}
\hline $\mathrm{X} 1.1$ & 1.000 \\
\hline $\mathrm{X} 2.1$ & 1.893 \\
\hline $\mathrm{X} 2.2$ & 3.307 \\
\hline $\mathrm{X} 2.3$ & 2.496 \\
\hline $\mathrm{Z} 1.3$ & 2.254 \\
\hline $\mathrm{Z} 1.4$ & 4.319 \\
\hline $\mathrm{Z} 1.5$ & 2.816 \\
\hline $\mathrm{Y} 1.1$ & 2.773 \\
\hline $\mathrm{Y} 1.2$ & 4.439 \\
\hline $\mathrm{Y} 1.3$ & 2.081 \\
\hline
\end{tabular}

Sumber: data diolah (2020)

Indikator variabel terbebas dari multikolinieritas kurang dari 5 dengan diuji menggunakan Smart PLs, oleh karena data sudah terbebas dari syarat analisis dengan Smart PLs.

Tabel 4: Hubungan antara latent variabel dan sekaligus menjawab hipotesis yang telah diuji

\begin{tabular}{|l|c|c|c|}
\hline $\begin{array}{l}\text { Laten } \\
\text { variabel }\end{array}$ & $\begin{array}{c}\text { Original } \\
\text { Sampel }\end{array}$ & $\begin{array}{c}\mathrm{t}- \\
\text { statistik }\end{array}$ & P-value \\
\hline $\mathrm{X} 1-\mathrm{Z}$ & 0.063 & 0.656 & 0.512 \\
\hline $\mathrm{X} 2-\mathrm{Z}$ & -0.311 & 2.588 & 0.010 \\
\hline $\mathrm{X} 1-\mathrm{Y}$ & -0.088 & 0.944 & 0.346 \\
\hline $\mathrm{X} 2-\mathrm{Y}$ & -0.370 & 2.991 & 0.003 \\
\hline $\mathrm{Z}-\mathrm{Y}$ & 0.596 & 0.638 & 0.000 \\
\hline $\mathrm{X} 1-\mathrm{Z}-\mathrm{Y}$ & 0.037 & 0.638 & 0.524 \\
\hline $\mathrm{X} 2-\mathrm{Z}-\mathrm{Y}$ & -0.186 & 2.446 & 0.015 \\
\hline
\end{tabular}

Sumber: ${ }^{a}$ run by bootstrapping in PLS software

Tabel 4 menunjukkan bahwa hasil hipotesa, H1 tidak signifikan sehingga pengaruh variabel orientasi belajar tidak mempunyai pengaruh terhadap variabel human capital secara langsung. H2 signifikan, variabel Komitmen mempunyai pengaruh secara langsung terhadap human capital. H3 tidak signifikan karena variabel komitmen mempunyai pengaruh langsung terhadap kinerja UKM. H4 tidak signifikan, variabel komitmen tidak mempunyai pengaruh secara langsung terhadap kinerja UKM. H5 mempunyai pengaruh signifikan secara langsung antara variabel human capital terhadap kinerja UKM. H6 menunjukkan variabel orientasi belajar mempunyai pengaruh secara tidak langsung dan tidak signifikan terhadap variabel kinerja UKM melalui human capital. Sedangkan H7 menunjukkan pengaruk tidaklangsung dan signifikan terhadap kinerjaUKM melalui human capital. Dari hasil analisis Smart PLs pada tabel 4 mencerminkan bahwa adanya pengaruh secara langsung dan secara tidak langsung dengan persamaan sebagai berikut:

$Z=0,063 X 1-0.311 X 2$
$Y=-0.126 X 1-0.184 X 2+0.596 Z$

Gambar 4 : Model hubungan variabel yang dimodifikasi

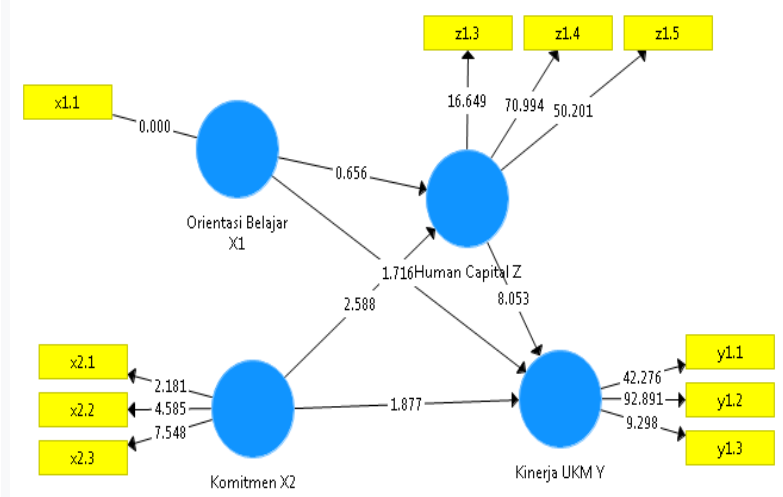

Sumber: data diolah (2020)

\section{SIMPULAN}

Variabel orientasi belajar tidak memberikan dampak yang signifikan terhadap kinerja UKM secara langsung, karena sebagian besar karyawan atau SDM yang bekerja di bisnis sekelas UKM masih belum banyak yang memperhatikan tentang peningkatan diri untuk menunjang aktivitas kinerja UKM. SDM yang berada pada sebagian besar 
UKM tingkat pendidikannya masih jarang yang tinggi. Sedangkan pengembangan dalam SDM menjadi penting jika para pemilik UKM memberikan dorongan untuk menambah wawasan kemampuan lewat belajar baik secara langsung maupun tidak langsung, hal ini dapat diketahui dari komitmen mempunyai hubungan terhadap human capital. Komitmen untuk menambah wawasan melalui kemampuan human capital menjadi sangat diperhatikan. Human capital mempunyai hubungan dan pengaruh yang sangat signifikan karena ini merupakan hasil usaha yang telah dilakukan oleh UKM dalam bidang peningkatan profitabilitas atau laba usaha, perputaran modal menjadi lebih baik. Peningkatan pemasaran juga memberikan dampak terhadap usaha UKM dari volume penjualan yang terus meningkat, marketshare yang semakin luas serta pangsa pasar menjadi bagian yang meningkat. Banyak pelanggan baru dan menjadi potensial, sehingga harapan UKM dapat bersaing dalam pasar bebas. Oleh karena itu, kinerja UKM telah memberikan harapan bagi besar untuk dapat maju dengan peningkatan kemanpuan SDM melalui human capital.

\section{Saran}

UKM menjadi tolok ukur keberhasilan perekonomian suatu negara karena pertumbuhan UKM semakin meningkat dan UKM tidak rentan dalam menghadapi krisis ekonomi dari semua sektor. Oleh karena itu perlu dukungan dari semua elemen baik pemerintah, pendidikan tinggi, kepedulian SDM sendiri untuk mau maju dalam pengembangan diri. Disamping itu, perlu melakukan bentuk orientasi belajar yang menarik bagi UKM, hal ini akan mempengaruhi peningkatan human capital bagi pribadi pengelola bisnis yaitu UKM, sehingga kinerja UKM dapat dikelola dengan baik untuk menuju pasar global

\section{DAFTAR PUSTAKA}

Andriani, N. 2012. "Model Hubungan Modal Sosial, Kompetensi Pemasaran (Marketing Intelligence Dan Marketing Innovation) Dalam Mempengaruhi Kinerja Pemasaran.' Jurnal Aplikasi Manajemen: 50-59.

Cepi, Triatna. 2015. Perilaku Organisasi. Bandung: PT.Remaja Rosdakarya.

Chandler, G., \& Hanks, S.H. 1994. "Market Attractiveness, ResourceBased Capabilities, Venture Strategies and Venture Performance." Journal of business venturing $\quad 9(4)$ : 323 http://biblioteca.clacso.edu.ar/clacso /otros/20111218115541/4.conf3.pdf.

Chong, S. 2008. "Success in Electronic Commerce Implementation: A Cross Country Study of Small and Medium Sized Enterprises.” Journal of Enterprise Information Management 21(5): 468-92.

Dae-Bong, K. 2009. "Human Capital and Its Measurement." The 3rd OECD World Forum on Statistics, Knowledge and Policy.

Ferdinand, A. 2005. "Modal Sosial." Upacara Penerimaan Jabatan Guru Besar dalam Ilmu Marketing Fakultas Ekonomi Universitas Diponegoro.

Frimayasa, Agtovia, and Suparman $\mathrm{Hi}$ Lawu. 2020. "Pengaruh Komitmen Organisasi Dan Human Capital Terhadap Kinerja Pada Karyawan Pt . Frisian Flag." 9(1): 36-47.

J. Paul Peter, Jerry C. Olson. 2001. Perilaku Konsumen Dan Strategi Pemasaran. Edisi keem. Jakarta: Erlangga.

Julita, Santi., Rafaei Wan. 2010. "Relationship of Organizational Commitment, Locus of Control, and Readiness to Change among Nurses. Psycho Behavioral Science and 
Quality of Life:The 6th International Postgraduateresearchcolloquium." Psycho behavioral science and quality of life:The 6th international postgraduateresearchcolloquium: 2010.

Kesi, Widjajanti, Sugiyanto Eviatiwi Kusumaningtyas, and Marka Mira Meilia. 2013. "Strategi Pengembangan Kinerja Pemasaran Melalui Human Capital Dan Social Capital Dengan Kemampuan Inovasi Sebagai Variabel Pemediasi." Journal of Chemical Information and Modeling 53(9): 1689-99.

Kozlenkova, Irina V, Stephen A Samaha, and Robert W Palmatier. 2013. "Resource-Based Theory in Marketing."

Marko, G. 2013. "Human Capital and Knowledge Audit as the Competitive Advantage of Companies." Net Journal of Social Sciences 1(1): 1-4.

Nurainun, H. R. 2008. “Analisis Industri Batik Di Indonesia." Fokus Ekonomi: 124-35.

Piazza-Georgi, B. 2002. "The Role of Human and Social Capital in Growth: Extending Our Understanding." Cambridge Journal of Economics 26(4): p461-79.

Pramadani, Ayu Bianda, and Fajrianthi. 2012. "Hubungan Antara Komitmen Organisasi Dengan Kesiapan Untuk Berubah Pada Karyawan Divisi Enterprise Service (DES) Telkom Ketintang Surabaya." Jurnal Psikologi Industri dan Organisasi 1 No 2(02): 102-9.

Schultz, Theodore W. 1961. "Investment in Human Capital." The American Economic Review 51(1): 1-17.

Sugiyono. 2006. Metode Penelitian Kuantitatif, Kualitatif Dan $R \& D$. Bandung: Alfabeta.
Surin, E.F, O.T Edward, H.F Hussin, and I.A Wahab. 2017. "Recognising the Importance of Strategic Business Network on Business Performance of SME Manufacturing Firm in Malaysia: Analysing The Moderating Influence of Human Capital and Business Environment." International Journal of Arts \& Sciences: 31-44.

Visagle, C. M., Steyn, C. 2011. "Organizational Commitment and Responses to Planned Organizational Change: Anexploratorystudy." SouthernAfricanBusinessReview 15(3): 2011.

Widodo, Widodo. 2009. "Model Pengembangan Human Capital Dalam Konteks Modal Sosial." Benefit Jurnal Manajemen dan Bisnis 13(2): 69-103. 